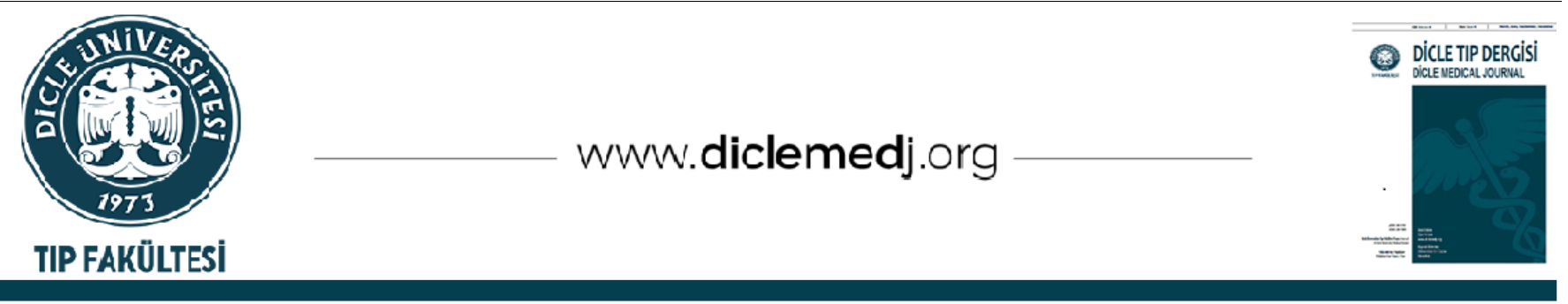

\title{
Asemptomatik Diabetes Mellituslu Hastalarda Diabetes Mellitus Süresi İle Koroner Flow Reserve (Cfr) Arasındaki İlişki
}

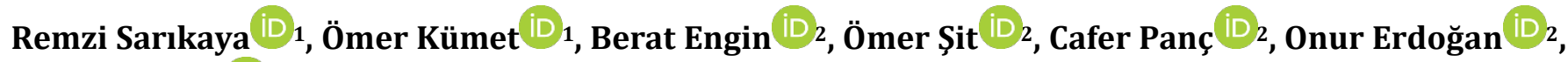 \\ Hüseyin Oflaz ${ }^{D_{2}}$
}

1 SBÜ Van Eğitim ve Araștırma Hastanesi, Kardiyoloji ABD, Van, Türkiye

2 İstanbul Üniversitesi İstanbul Tıp Fakültesi, Kardiyoloji ABD İstanbul, Türkiye

Geliş: 26.10.2021; Revizyon: 22.11.2021; Kabul Tarihi: 27.11.2021

Öz

Amaç: Çalışmamızda, asemptomatik diyabetik hastalarda diyabet süresinin artması ile gelişen koroner arter hasarının, non-invaziv, tekrarlanabilir ve basit bir yöntem olan koroner akım rezervi (CFR) ölçüm sonuçlarıyla kıyaslanması amaçlanmıştır.

Yöntemler: Çalışmaya bilinen koroner arter hastalı̆̆ı öyküsü olmayan, bağımsız hekimler tarafından çeşitli endikasyonlarla koroner anjiyografi yapılması planlanmış 83 diyabetik ve 31 diyabetik olmayan, ardışık 114 hasta alındı. Tüm hastalarda koroner anjiyografi öncesi transtorasik ekokardiyografi (TTE) ile koroner akım rezervleri hesaplandı.

Bulgular: Diyabetik hastalarda koroner akım rezervi (CFR) değerlerinin diyabetik olmayanlara göre anlamlı ölçüde düşük olduğu görüldü $(1.74+0.33 / 2.41+0.40, \mathrm{p}<0.001)$. Diyabetik hastalarda diyabet süresi ile CFR anlamlı düzeyde koreleydi $(\mathrm{r}=-0.368, \mathrm{p}<0.0001)$. Koroner anjiyografi yapılan diyabetik hastalarda ROC analizi ile CFR değerinin 1.65 'in altında olmasının, \% 80 sensitivite, \% 81 spesifite ile herhangi bir koroner arterde \% 50 ve üzeri darlık varlığını öngördüğü gösterildi (Eğri altında kalan alan 0,888 [ 0,811-0,965; p<0,0001]). CFR değeri 1.65'in altında olan hastalarda koroner anjiyografi sonrası revaskülarizasyon (PCI veya CABG) uygulanma oranı, medikal tedaviye göre anlamlı düzeyde yüksek saptandı $(\mathrm{p}=0.001)$.

Sonuç: Aterosklerozu erken dönemde, belirgin koroner arter hastalığı gelişmeden saptamak prognoz açısından son derece önemlidir. Efor testinin yapılamadığı veya düşük duyarlılık nedeniyle tercih edilmediği hastalarda, basit, ucuz ve non-invaziv bir yöntem olan CFR ölçümü de göz önünde bulundurulmalıdır. Bu hem koroner arter hastalığının tespitinde hem de prognozun öngörülmesine katkıda bulunacaktır.

Anahtar kelimeler: Koroner akım rezervi, diyabetes mellitus, koroner arter hastalığı

DOI: 10.5798/dicletip.1037845

Yazışma Adresi / Correspondence: Remzi Sarıkaya, Süphan, Hava Yolu Kavşağı 1. Kilometre, 65300 Edremit/Van, Türkiye e-mail: drremzisarikaya@gmail.com 


\title{
The Relationship Between Diabetes Mellitus Duration And Coronary Flow Reserve (Cfr) In Patients With Asymptomatic Diabetes Mellitus
}

\begin{abstract}
Objective: In our study, it was aimed to compare the coronary artery damage that develops with the increase of diabetes duration in asymptomatic diabetic patients with the results of coronary flow reserve (CFR) measurement, which is a noninvasive, reproducible and simple method.
\end{abstract}

Methods: A total of 114 consecutive patients, 83 diabetic and 31 non-diabetic, who had no known history of coronary artery disease and were planned to undergo coronary angiography for various indications by independent physicians, were included in the study. Coronary flow reserves were calculated by transthoracic echocardiography (TTE) before coronary angiography in all patients.

Results: Coronary flow reserve (CFR) values were found to be significantly lower in diabetic patients compared to nondiabetic patients $(1.74+0.33 / 2.41+0.40, \mathrm{p}<0.001)$. In diabetic patients, diabetes duration was significantly correlated with CFR ( $r=-0.368, p<0.0001)$. In diabetic patients who underwent coronary angiography, ROC analysis showed that a CFR value below 1.65 predicted the presence of stenosis of $50 \%$ or more in any coronary artery with $80 \%$ sensitivity and 81\% specificity (Area under the curve 0.888 [ $0.811-0.965 ; \mathrm{p}<0,0001]$ ). In patients with a CFR below 1.65, the rate of revascularization (PCI or $\mathrm{CABG}$ ) after coronary angiography was found to be significantly higher than medical treatment $(\mathrm{p}=0.001)$.

Conclusion: It is extremely important for prognosis to detect atherosclerosis at an early stage, before significant coronary artery disease occurs. CFR measurement, which is a simple, inexpensive and non-invasive method, should also be considered in patients for whom effort testing cannot be performed or is not preferred due to low sensitivity. This will contribute to both the detection of coronary artery disease and the prediction of prognosis.

Keyword: Coronary flow reserve, diabetes mellitus, coronary artery disease.

\section{GíRiş}

Diyabetik hastalarda en önemli mortalite nedeni kardiyovasküler hastalıklardır(KVH) ve kardiyovasküler olay riski $2-4$ kat daha fazladır ${ }^{1}$. Diabetes mellitus günümüzde koroner arter hastalığı eşdeğeri olarak kabul edilmektedir². Diyabetik olmayan hastalarda tüm ölümlerin \%30'u ateroskleroz ile ilişkili iken, diyabetik hastalarda bu oran \% 80'lere ulaşmaktadır ${ }^{3}$. Kalp yetersizliğinin diyabetik hastalarda bu artmış oranı, araştırmacıları erken teşhisin sağlanmasını amaçlayan çalışmalara yöneltmiştir.

Diyabetik hastalarda mikrovasküler hasarda yüksek kan şekeri düzeyinin etkili olduğu ifade edilmektedir ${ }^{4-5}$. Hipergliseminin yanında hipertansiyon, sigara, dislipidemi, obezite ve hiperhomosisteinemi gibi faktörler de mikroanjiopatiye neden olabilmektedir. Makroanjiopati gelişminde hiperglisemiden daha çok yaş, sigara, hipertansiyon, dislipidemi, obezite ve yüksek homosisteinemi gibi aterotrombozla ilgili risk faktörleriyle ilişkilidir. Tüm bu risk faktörleri inflamatuar bir süreç ve endotel disfonksiyonu sonucunda progresif vasküler duvar hasarına yol açar6. Vasküler endotel disfonksiyonun mikro ve makroanjiopati patogenezinde önemli rol oynadığı saptandığından bu konudaki çalışmalar hız kazanmıştır ${ }^{7-8}$.

Endotel fonksiyon bozukluğu aterosklerozun gelismesinde önemli rol oynamaktadır. Koroner anjiyografi koroner arterlerde damar lümenine doğru darlık yapan aterosklerotik lezyonları gösterebilmekte ancak koroner dolaşımın fizyolojisi ve endotel fonksiyonu konusunda yeterli bilgi vermemektedir. Koroner arter endotel fonksiyonu transtorasik ekokardiyografi (TTE) veya invazif olarak koroner anjiyografik yöntemlerle elde edilen koroner akım rezervi (coronary flow reserve, CFR) ölçümleri ilgi çekici hale gelmiştir9. 
Koroner damarların metabolik ihtiyaç halinde vazodilatasyona uğrayamamasının endotel fonksiyon bozukluğunun bir göstergesi olması prensibinden yararlanan CFR ölçümleri ile hem epikardiyal koroner arterlerin, hem de mikrovasküler koroner dolasımın durumunu güvenilir olarak tayin etmek mümkün olmaktadır ${ }^{10}$.

Çalışmamızda bilinen koroner arter hastalığı olmayan asemptomatik tip 2 diyabetik hastalarda epikardiyal koroner arter fonksiyon bozukluğunun ve mikrovasküler dolaşımdaki bozulmanın transtorasik ekokardiyografiyle, koroner akım rezervi ölçümü ile tespit edilmesi ve diyabet süresi ile ilişkisinin gösterilmesi amaçlanmıştır.

\section{YÖNTEMLER}

Çalışmaya İstanbul Tıp Fakültesi Kardiyoloji Anabilim Dalı'nda bağımsız hekimler tarafından çeşitli endikasyonlarla koroner anjiyografi yapılması kararı verilmiş, daha önce koroner anjiyografi yapılmamış, sol ventrikül ejeksiyon fraksiyonu $\geq \% 55$ ve $2 \mathrm{D}$ ekokardiyografide segmenter duvar hareket kusuru olmayan, 1875 yaş arasında, gönüllü onam formu alınmış, dişlama kriterlerine sahip olmayan, asemptomatik, 83 diyabetik ve 31 diyabet hastalığı olmayan (kontrol grubu) toplamda 114 hasta alınd. Koroner anjiyografi yapılmadan önce hastaların hangi grupta olduğunu bilmeyen bağımsız bir araştırmacı tarafindan TTE ile temel ekokardiyografik ölçümler ile beraber koroner akım görüntülemesi yapılarak CFR hesaplandı. Açlık kan şekeri $126 \mathrm{mg} / \mathrm{dl}$ ' nin üzerinde olanlar ile bilinen diyabetes mellitus tanısı nedeniyle tedavi görmekte olanlar diyabetik olarak kabul edildi. Diyabetik hastaların sistolik kan basıncı 140 mmHg'nın, diyastolik kan basıncı 90 mmHg'nın üzerinde olanlar ya da antihipertansif kullanım hikâyesi olanlar hipertansif olarak kabul edildi. Diyabet ve hipertansiyon hastalığı olanların, bu hastalıklarının süresi ve kullanmakta oldukları ilaçlar kayıt edildi. Tüm hastaların HBA1C, spot idrarda mikroalbümin/kreatinin, kolesterol ve temel biyokimyasal değerleri bakıldı. Tüm hastaların koroner anjiyografi öncesi varsa yapılmış noninvaziv iskemi araştırma testlerinin (miyokard perfüzyon sintigrafisi ve/veya "treadmill" egzersiz testi) sonuçları not edildi. Açlık LDL seviyesi $130 \mathrm{mg} / \mathrm{dl}$ ' nin üzerinde olanlar ya da statin kullanım öyküsü olanlar hiperkolesterolemik, açlık trigliserid düzeyi $150 \mathrm{mg} / \mathrm{dl}$ 'nin üzerinde olanlar ya da antilipidemik ilaç kullanım öyküsü olanlar hipertrigliseridemik olarak belirlendi. Sigara kullanımı, sigara içenler, hiç içmemiş ve terk etmiş olanlar olarak belirlendi. Tüm hastaların BMI'sı hesaplandı. Hastalara yapılan değerlendirmeler sonucunda koroner anjiyografi yapılması kararını veren hekimler tarafından koroner anjiyografileri yapıldı. Koroner anjiyografi sonuçları mevcut kılavuzlar ışığında yorumlandı. Koroner arterlerde plak veya darlık olmaması 'normal koroner arterler'; \%0-50 aralığında darlık olması 'koroner arterlerde anlamlı darlık yapmayan darlıklar' ; $\% 50$ 'nin üzerinde olması 'koroner arter hastalığı'; \% 70 in üzerinde darlık olması ise revaskülarizasyon ihtiyacı olması olarak değerlendirildi.

Koroner arter hastalığını düşündüren semptomu olmasl, daha önce koroner anjiyografi yapılmış olması, koroner arter hastalığı olması, sol ventrikül hipertrofisi, kardiyomiyopati, miyokardit, sol ventrikül sistolik işlev bozukluğu, orta-ciddi kapak hastalığı, kronik böbrek ve karaciğer yetersizliği, aktif malignite, aktif enfeksiyon, kronik obstruktif akciğer hastalığl, kontrolsüz hipertansiyon (işlem öncesi kan basıncı > $140 / 90 \mathrm{mmHg}$ ), morbid obezite bulunması, ekokardiyografik görüntünün koroner akımın görüntülenmesi için yetersiz olması dışlama kriterleri olarak kabul edilmiştir. Çalışma için 
İstanbul Tıp Fakültesi 24.09.2013 tarihli 1333 sayı ile etik kurulundan onay alındı.

Koroner akım rezervi ve rezistans ölçümü: CFR ölçümleri ve temel ekokardiyografik incelemeleri VIVID 7 (GE, general electric) ekokardiyografi cihazında ve $3 \mathrm{mHz}$ prob ile yapıldı. Sol lateral dekübitis pozisyonunda midklaviküler hattın 4.-5. interkostal aralığı kestiği noktada, sol ventrikülün apikal 2 boşluk uzun eksen görüntülenmesinde, optimal velosite $12-15 \mathrm{~cm} / \mathrm{sn}$ olacak şekilde renkli Doppler ile LAD mid-distal akımı görüntülendi. "Pulsed-wave" Doppler aracılığı ile önce koroner akım hızının bazal sistolik (SAPVb) ve diyastolik akım değeri (APVb) ölçüldü. Daha sonra 5 dakika süre ile $0,56 \mathrm{mg} / \mathrm{kg}$ dipiridamol infüzyonu uygulandı. Eğer kalp hızında bazale göre $\% 10^{\prime}$ dan daha az artış olduysa 2 dakika süre ile $0,28 \mathrm{mg} / \mathrm{kg}$ dipiridamol infüzyonu ek olarak yapıldı. Dipiridamol infüzyonu bittikten 2 dakika sonra pik sistolik akım hızı (SAPVh) ve hiperemik pik diyastolik akım hızı (APVh) ölçüldü (Şekil 1). Dipiridamol infüzyonu süresince, öncesi ve sonrası sık aralıklarla KB takibi yapıldı. Bu ölçümlerden CFR hesaplandı (APVh/APVb).

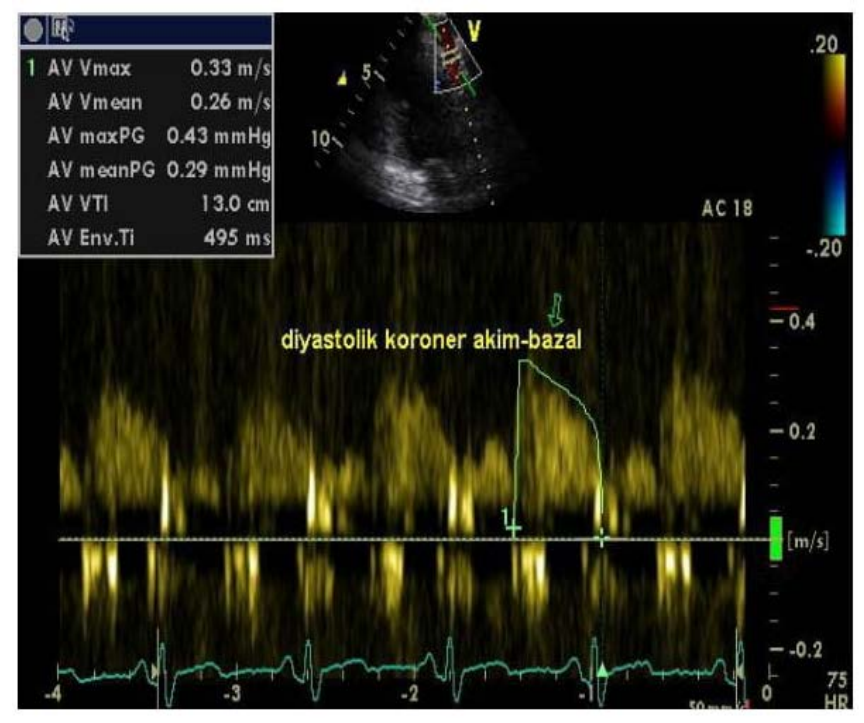

Şekil 1 -A TTE' de distal LAD'nin "pulsed wave" Doppler ekokardiyografi ile elde edilen bazal diyastolik akım paterni

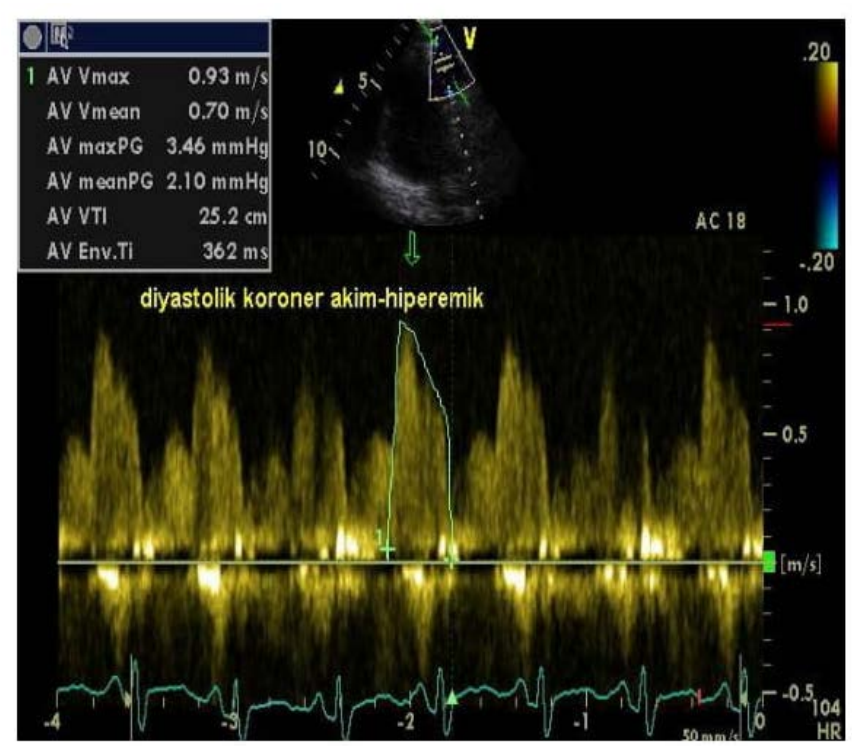

Şekil 1 -B TTE' de distal LAD'nin "pulsed wave" Doppler ekokardiyografide saptanan hiperemik diyastolik akım paterni

APVb : Ortalama bazal diyastolik akım hızı ("basal average peak velocity")

APVh : Ortalama hiperemik diyastolik akım hızı ("hyperemic average peak velocity")

\section{İstatistiksel Analiz}

İstatistiksel analizler SPSS (SPSS Inc., Chicago, Illinois) programı kullanılarak yapıldı. Hemodinamik sürekli değişkenler \pm ortalama standart sapma olarak ifade edildi.

Sinıflandırılan veriler sayı ya da sıklık olarak ifade edildi. Parametrik testle yapılan değişkenlerde independent samples t test; nonparametrik testle yapılan değişkenlerde mannwhitney $\mathrm{u}$ test kullanıldı. P değeri $<0.05$ olması anlamlı kabul edildi.

\section{BULGULAR}

1) Diyabetik grup ile diyabetik olmayan grubun karşılaștırılması

Çalışmaya toplamda 114 hasta dahil edildi. Grubun \%72' si (n=83) diyabetik, \%28' i (n=31) diyabetik olmayan (non-diyabetik) grup oluşturmaktaydı. Diyabetik hasta grubunun \%48'i (n=41) erkek, \%52'i (n=42) kadın 
hastaydı. Non-diyabetik hasta grubunun \%51'i $(n=16)$ erkek, \%49' u (n=15) kadın hastaydı.

Gruplar arasında; yaş, boy, kilo, vücut kitle indeksi (BKI), vücut yüzey alanı (BSA) ve kan basınçları açısından anlamlı fark yoktu. Laboratuvar değerlerinden kreatinin, hemoglobin, kolesterol değerleri arasında anlamlı fark yokken; spot idrarda mikroalbümin/kreatinin oranı diyabetik hasta grubunda anlamlı düzeyde yüksek saptandı. $(\mathrm{p}=0.029)$. Kontrol grubunun glukoz düzeyi $84.9 \pm 8.3 \mathrm{mg} / \mathrm{dL}$ ve diyabetik hasta grubunun glukoz düzeyi $165 \pm 68 \mathrm{mg} / \mathrm{dL}$ olarak saptanmiştır. Kontrol grubunun HbA1c düzeyi $\% 5,0 \pm 0.3$ ve diyabetik hasta grubunun HbA1c düzeyi $\% 7,9 \pm 1.9$ idi. Glukoz ve HbA1c düzeyleri açısından iki grup arasında anlamlı farklılık izlenmiştir (Tablo 1).

Tablo I: Temel parametrelerin kıyaslanması

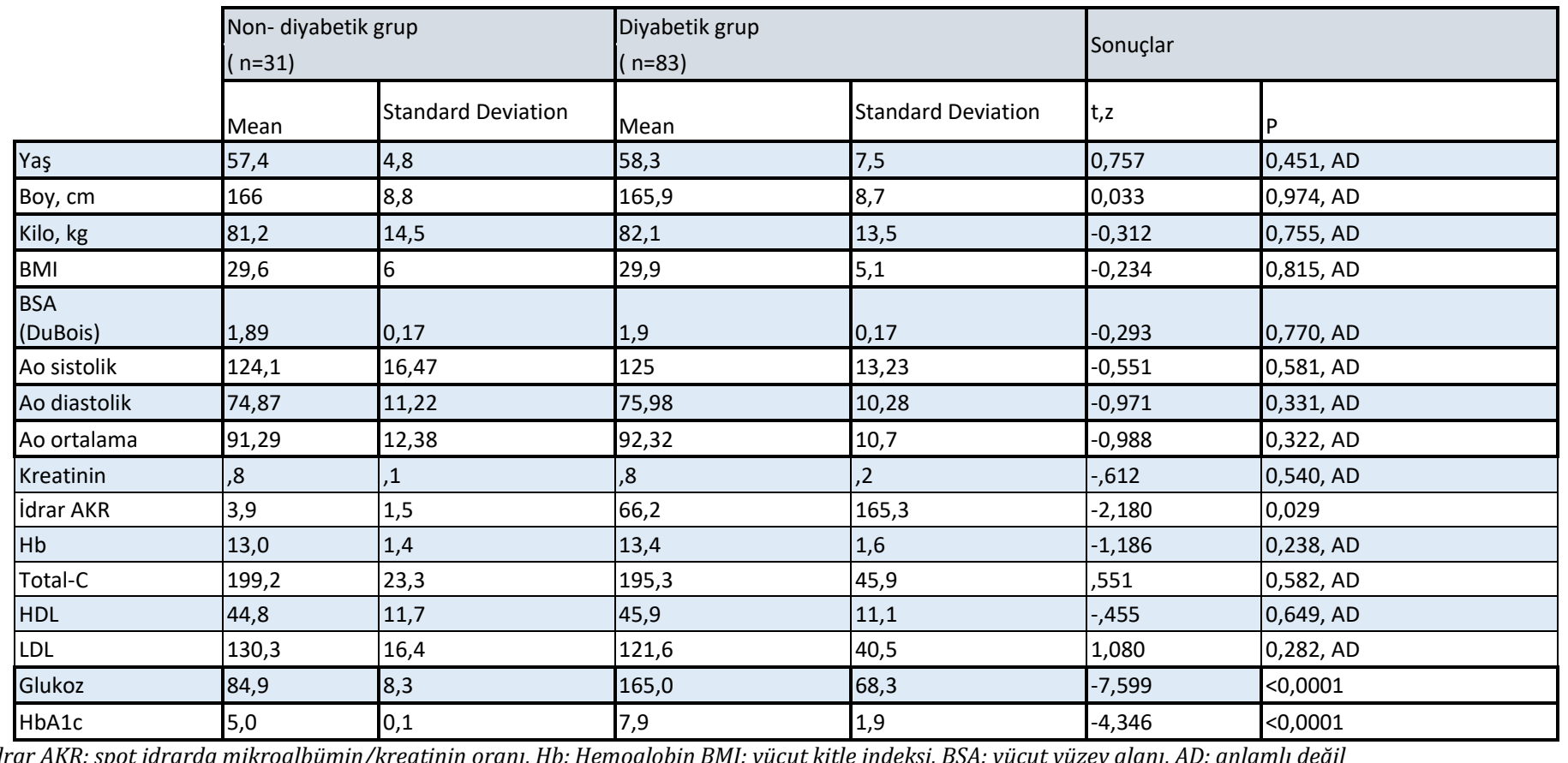

Diyabetik ve nondiyabetik gruptaki hastaların ekokardiyografik sol ventrikül M-mode ölçümleri ve diyastolik fonksiyon parametreleri karşılaştırılmıştır (Tablo 2). Hastaların sistolik fonksiyonları, duvar kalınlıkları, sol ventrikül sistolik ve diastolik volümleri, sol ventrikül kas kitleleri arasında istatiksel olarak anlamlı farklılık saptanmadi. Ancak diastolik fonksiyon parametleri değerlendrimesinde E/A oranı kontrol grubunda $1.09 \pm 0.29$, diyabetik grupta $0.81 \pm 0.18(\mathrm{p}<0.000)$ olarak saptanmıştır. Diyabetik grubun diyastolik parametreleri genel olarak bozulmuş olup, özellikle relaksasyon bozukluğu saptanmıştır. 
Tablo II: Diyabetik ve nondiyabetik grupta sol ventrikül ekokardiyografi parameterlerin değerlendirilmesi

\begin{tabular}{|c|c|c|c|c|c|c|}
\hline \multirow[b]{2}{*}{ Ekokardiyografi } & \multicolumn{2}{|c|}{$\begin{array}{l}\text { Non-diyabetik grup } \\
(n=31)\end{array}$} & \multicolumn{2}{|c|}{$\begin{array}{l}\text { Diyabetik grup } \\
(n=83)\end{array}$} & \multicolumn{2}{|c|}{ Sonuçlar } \\
\hline & Mean & Standard Deviation & Mean & Standard Deviation & $t, z$ & $P$ \\
\hline IVS & 1,04 & 0,13 & 1,08 & 0,14 & $-1,443$ & $0,149, A D$ \\
\hline PW & 1,00 & 0,11 & 1,01 & 0,13 &,- 580 & $0,562, A D$ \\
\hline LVIDd & 4,57 & 0,31 & 4,62 & 0,38 &,- 700 & $0,485, A D$ \\
\hline LVIDs & 2,76 & 0,33 & 2,84 & 0,33 & $-1,118$ & $0,266, A D$ \\
\hline LVEDV (Teich) & 96,44 & 15,02 & 99,40 & 18,85 & $-1,361$ & $0,174, A D$ \\
\hline LVESV (Teich) & 29,13 & 8,77 & 31,17 & 8,77 & $-1,108$ & $0,270, A D$ \\
\hline SV (Teich) & 67,31 & 10,63 & 68,23 & 14,06 &,- 330 & $0,742, A D$ \\
\hline LVEF (Teich) & 70,32 & 5,85 & 68,13 & 5,67 & 1,819 & $0,072, A D$ \\
\hline LVmass & 166,93 & 34,07 & 175,09 & 33,64 & $-1,149$ & $0,253 \mathrm{AD}$ \\
\hline LVmass Indx & 88,11 & 14,78 & 92,60 & 17,74 & $-1,257$ & $0,211, A D$ \\
\hline RWT & 0,44 & 0,05 & 0,44 & 0,07 &,- 305 & $0,761, A D$ \\
\hline E & 80,74 & 17,92 & 63,67 & 14,31 & 5,278 & $<0,0001$ \\
\hline A & 76,29 & 15,47 & 79,47 & 15,13 &,- 992 & $0,323, A D$ \\
\hline$E^{\prime}$ & 8,45 & 2,50 & 6,41 & 1,89 & $-4,117$ & $<0,0001$ \\
\hline$E / A$ & 1,09 & 0,29 & 0,81 & 0,18 & $-4,964$ & $<0,0001$ \\
\hline$E / E^{\prime}$ & 10,16 & 3,29 & 10,47 & 2,95 &,- 675 & $0,500, A D$ \\
\hline
\end{tabular}

Veriler ortalama değer \pm standart deviasyon olarak belirtilmiştir. IVS: İnterventriküler septum kalınlı̆̆ı, LVIDd: Sol ventrikül diyastolik çapı, LVIDs: Sol ventrikül sistolik çapı, PW: Arka duvar kalınlığı, LVMass: Sol ventrikül kütlesi, LVMass Indx: Sol ventrikül kütle indeksi, E': Doku Doppler E dalgası, AD: anlamlı değil,

Kontrol grubunun koroner akım rezervi (CFR) $2.41 \pm 0.40$ ve diyabetik hasta grubunun 1.74

\pm 0.33 idi. Her iki grup arasında CFR yönünden anlamlı farklılık saptanmıştır $\quad(\mathrm{p}<0.001)$. Farklılığın oluşmasında hem bazal koroner akımların diyabetik grupta daha yüksek olması $(29,2+8.87 / 24,26+3,92, p=0.011)$ hem de hiperemik koroner akımların daha düşük olmasi $(49,46+13,44 / 58,39+12,43, p=0.000)$ katkıda bulunmuştur (Tablo 3).

Tablo III: Non-diyabetik grup ile diyabetik grubun koroner akım rezervi yönünden karşılaştırılması

\begin{tabular}{|c|c|c|c|c|c|c|}
\hline \multirow{2}{*}{$\begin{array}{l}\text { Koroner Doppler } \\
\text { Görüntüleme Sonuçları }\end{array}$} & \multicolumn{2}{|c|}{$\begin{array}{l}\text { Non-Diyabetik grup } \\
(\mathrm{n}=31)\end{array}$} & \multicolumn{2}{|c|}{$\begin{array}{l}\text { Diyabetik grup } \\
(\mathrm{n}=83)\end{array}$} & \multicolumn{2}{|c|}{ Sonuçlar } \\
\hline & Mean & Standard Deviation & Mean & Standard Deviation & $t, z$ & $\mathrm{P}$ \\
\hline APVb & 24,26 & 3,92 & 29,12 & 8,87 & $-2,528$ & 0,011 \\
\hline APVh & 58,39 & 12,43 & 49,46 & 13,44 & $-3,507$ & $\mid<0,001$ \\
\hline CFR & 2,41 & 0,40 & 1,74 & 0,33 & $-6,778$ & $\mid<0,001$ \\
\hline
\end{tabular}

Veriler ortalama değer \pm standart deviasyon olarak belirtilmistir. APVb: bazal pik diyastolik hız, APVh: hiperemik pik diyastolik hız, CFR: koroner akım rezervi

\section{1) Diyabetik hasta gruplarının karşılaştırılması}

Diyabetik hastalar, diyabet sürelerine göre 3 gruba sınıflandırılmıştır (DM süresi 0-5 yıl arası grup 1, 5- 10 yıl arası grup 2, 10 yıl üstü olanlar grup 3). CFR değerleri diyabetik olmayan grup ile kiyaslandığında tüm gruplarda nondiyabetik gruba göre anlamlı olacak şekilde düşük saptandı (her grup için p<0.001). Ancak diyabetik olan her 3 grup birbirleriyle kıyaslandığında CFR değerleri arasında anlamlı bir fark saptanmadi. Diyabetik hastalarda diyabet süresi ile sol ventrikül sistolik ve diastolik parametreler, BMI ve HbA1C arasinda anlamlı bir korelasyon saptanmazken, CFR ile ters yönde olacak şekilde $(\mathrm{r}=-0.368, \mathrm{p}<0.0001)$ anlamlı korelasyon saptandı (Şekil 2). 


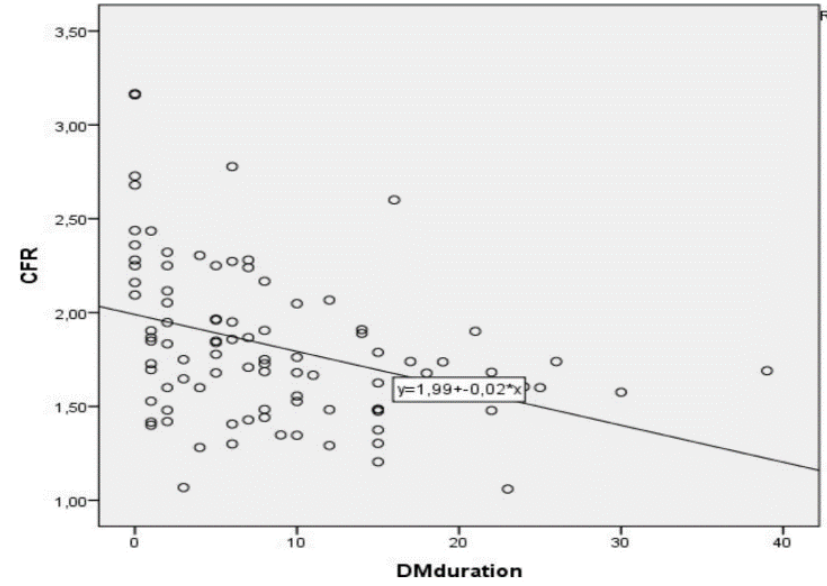

Şekil 2: Diyabet süresi ile CFR ilişskisi

Toplam 83 diyabetik hastanın 32'si ( \%38,5) insülin kullanmaktayken, 51'i ( \%61,5) insülin kullanmamaktaydı. İnsülin kullanan grupta HbA1C değerinin insülin kullanmayan gruba göre daha yüksek seyrettiği görüldü. $(9.32+$ $1.99 / 6.98+1.20, \mathrm{p}<0.0001)$. İnsülin kullanan grupta CFR ( $\mathrm{n}=32,1.63+0.24)$, kullanmayan gruba göre $(n=51,1.80+0.36)$ anlamlı olacak şekilde düşüktü $(\mathrm{p}=\quad$ 0.045).Diyabetik hastalarda koroner akım rezervi ( CFR ) ile $\mathrm{HbA1C}$ arasında ters yönde olacak şekilde ( $\mathrm{r}=$ $0.336, p=0.003$ ) anlamlı korelasyon saptandı (Şekil 3).

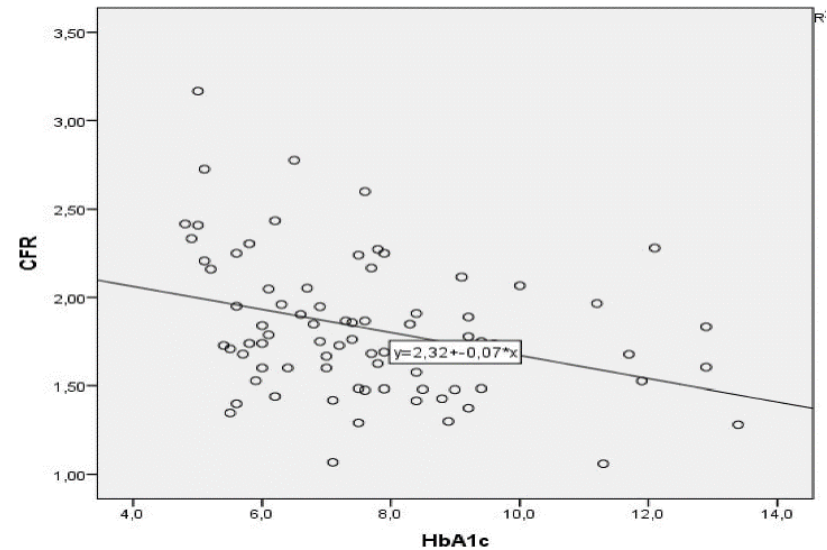

Şekil 3: CFR ile HBA1C arasındaki ilişki

3-) CFR değerleri ile koroner anjiyografi sonuçları arasındaki ilişki

83 diyabetik hastadan koroner anjiyografi yaplan 79 tanesinde koroner anjiyografi sonuçları darlık düzeylerine göre sınıflandırıldı.
Darlık saptanmayan hastalar (grup 0), \%50'e kadar olan darlıklar (grup 1), sol ana koroner dışı koroner arterlerde \%50-70 arasındaki darlıklar (grup 2) ve sol ana koroner arterde $>\% 50$ ile diğer koroner arterlerde $>\% 70$ darlık olanlar (grup 3) diye 4 grup altında incelendi. Koroner anjiyografi yapılan diyabetik hastalarda ROC analizi ile koroner arter darlığını ön gören CFR cut-off değerleri hesaplandı. CFR değerinin

1.65 olması $\% 80$ sensitivite, $\% 81$ spesifite ile herhangi bir koroner arterde $\% 50$ ve üzeri darlık varlığını ön görmektedir (Şekil 4). Eğri altında kalan alan: 0,888 ( 0,811-0,965; p< 0,0001 ) saptandi.

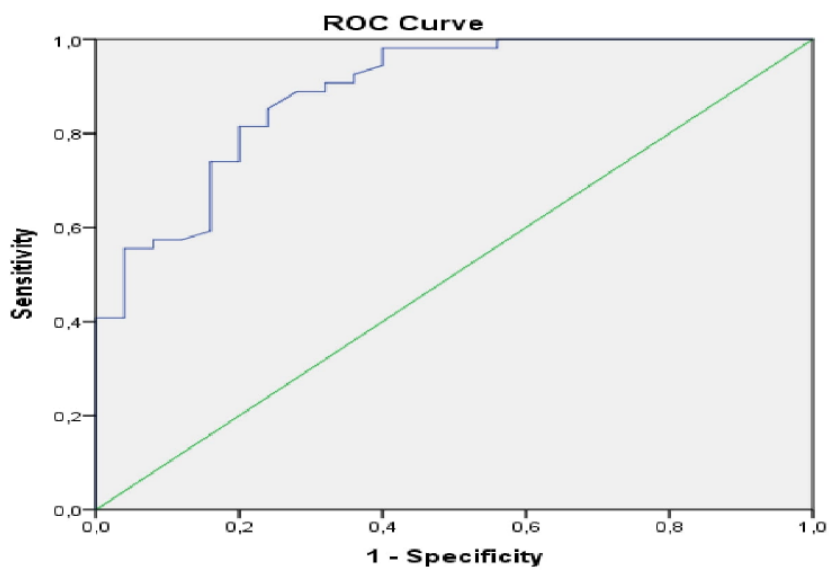

Şekil 4: CFR cut-off değeri belirleme analizi

Aynı zamanda CFR değerleri ile koroner arter hastalığı ciddiyeti arasında anlamlı korelasyon saptand. $(\mathrm{r}=-0.653, \mathrm{p}<0.0001)$ (Şekil 5).

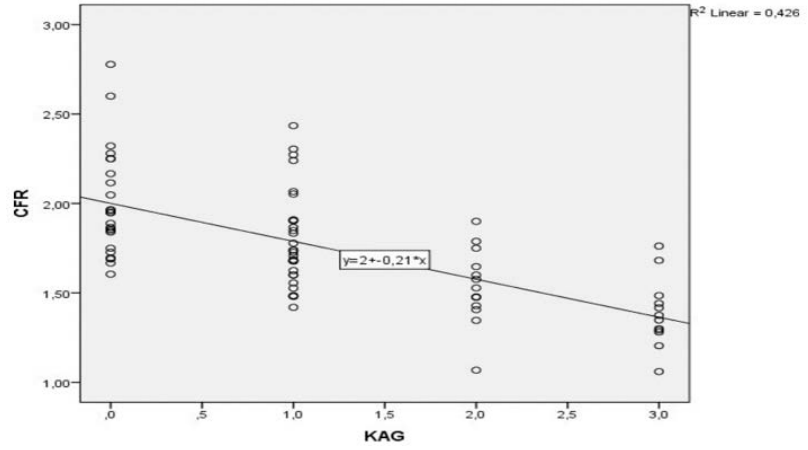

Şekil 5: CFR değeri ile koroner arter hastalığı arasındaki ilișki

KAG sütununda $0=$ normal koroner arterler, $1=$ anlaml darlı $k$ yapmayan darlıklar, 2=\%50-70 arası darlıklar, 3= >\%70 darlıklar 
Koroner arter hastalığı tespit edilip uygulanan tedavi stratejisine göre medikal tedavi, PCI (PTCA+STENT), koroner arter by-pass greft (CABG) olarak gruplara ayrıld. Koroner anjiyografi yapılan 79 hastanın 68 tanesine medikal takip kararı verilirken; 5 tanesine stent uygulanmış, 6 tanesine de CABG operasyonu yapılmıştır. ROC analizi ile koroner arter darlığı göstergesi olarak belirlenen CFR:1.65 değerine göre hastalar sinıflandirıldı. PCI veya CABG uygulanan hastaların \%81,8'inde $(n=9)$ CFR < 1.65 saptanirken, \%18,2 sinde ise CFR >1.65 saptand. Medikal tedavi kararı verilen hastaların \%29,4'ünde $(n=20) \quad$ CFR $<1.65$ saptanırken, \%70,6'sinda ( $n=48$ ) CFR >1.65 saptandı. PCI veya CABG uygulanan hastalarda CFR değerinin < 1.65 veya > 1.65 olması arasında anlamlı farklılık saptanmıştır. $(\mathrm{p}=0.001)$.

Uygulanan tedavi şekline göre CFR ile tedavi şekli arasında medikalden CABG'ye doğru anlamlı derecede korelasyon tespit edildi $(\mathrm{r}=$ 422, $\mathrm{p}<0.0001$ ) (Şekil 6).

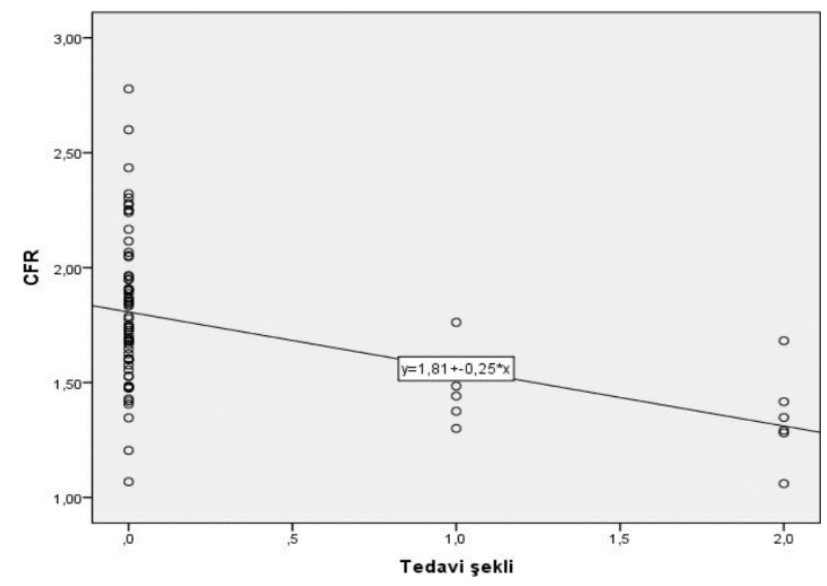

Şekil 6: CFR değeri ile uygulanan tedavi arasındaki ilişki Tedavi şekli $0=$ medikal tedavi, $1=P T C A+S T E N T, 2=C A B G$

\section{TARTIŞMA}

Diyabetlilerde ateroskleroz daha erken yaşlarda ortaya çlkar, daha hızlanmış bir seyir gösterir, multi-segmenter tutulumlu ve daha yaygındır. Özellikle insülin rezistansının bulunduğu Tip 2 DM'da hiperinsülinemi, makrovasküler hastalık oluşumunda etkili olmaktadır. Aterosklerotik lezyonlara bağlı komplikasyonlar daha sık meydana gelmektedir. Bu hastalar girişimsel kardiyoloji veya cerrahi yöntemlerle revaskülarizasyon tedavileri uygulanan hastaların da önemli bir bölümünü olușturmaktadır. Diabetes mellitusun makrovasküler düzeyde yaptığı aterosklerozun yanında mikrovasküler komplikasyonları da çok önemlidir. Koronerleri normal bulunan olguların da \%50 ve daha fazlasında koroner akım rezervinin azalmış olduğu bilinmekte ve bunun da koroner mikrodolaşımın bozuk olmasından kaynaklandığı belirtilmektedir ${ }^{11}$.

Diyabet hastalarında komplikasyonlarının temelinde endotel fonksiyon bozukluğu mevcuttur. Diabetes mellitus varlığında endotelde homeostatik denge bozularak, vazokonstriksiyon, tromboz, düz kas hücrelerinde proliferasyon ve damar duvarında lipid birikimi meydana gelmektedir. $\mathrm{Bu}$ süreç aterosklerotik damar plağı oluşumu ile sonuçlanmaktadır. Endotel fonksiyon bozukluğunun invazif olmayan yöntemlerle değerlendirilmesinde çeşitli tetkikler bulunmaktadır. Karotis intima-media kalınlığı, brakial arter USG ile endotel bağıml vazodilatasyonun değerlendirilmesi, transtorasik ekokardiyografi ile koroner akım rezerv ölçümü endotel fonksiyon bozukluğunu gösteren invazif olmayan tanı yöntemleridir ${ }^{12}$. $\mathrm{Bu}$ yöntemler yüksek riskli hastalarda aterosklerozu erken evrede tespit etmek için faydalı görülmektedir. Ayrıca risk sinıflamasinda ve tedavinin düzenlenmesinde faydaları vardır.Diyabetli hastaların erken dönemlerinde asemptomatik seyretmeleri nedeniyle KAH tanısı koymak zor olmaktadır. Diyabetik KAH tanısı olan hastaların klinik sonlanımları kötü olduğundan ve erken tedavi ile bu engellenebileceğinden erken dönemde tanı koymak önemlidir ${ }^{13}$. Asemptomatik tip 2 diyabetik hastalarda miyokard iskemisini tespit etmek için egzersiz testinin kolay uygulanabilir 
olması, ucuz olması nedeni ile ilk basamak test olarak tercih edilmektedir ${ }^{14}$. Bu hastalarda egzersiz EKG testinin duyarlılığı \%75, özgüllüğü ise $\% 77$ olarak bulunmuştur ${ }^{15}$. Ancak diyabetik hastalarda obezitenin sık olması, periferik arter hastalığı varlığ efor testinin kullanımını kısitlamaktadır. Miyokard perfüzyon sintigrafisi, sessiz iskemiyi saptamak için kullanılabilmektedir. Ancak diyabetik hastalardaki obezite, meme interpozisyonu, hipertansiyon ve kardiyomiyopati gibi nedenler miyokard perfüzyon sintigrafisinde yanlış pozitif sonuçlara yol açmaktadır. Diyabetik kardiyomiyopati, iskemiyi taklit eden talyum defektlerine neden olmaktadır ${ }^{16}$. Miyokard perfüzyon sintigrafisinin yoğun radyasyon içermesi de testin tarama testi olmasını ve periyodik olarak yapılmasını kısıtlamaktadır.

CFR'ın basit, ucuz, radyasyon içermemesi ve yatakbaşı uygulanabilir olması nedeniyle asemptomatik diyabetik hastalarda sesiz iskemiyi ve koroner arter hastalığını tarama yöntemi olarak CFR'ın rolünü araştırdık. Endotele bağlı olmayan bir koroner vazodilatatör infüzyonu sonrası maksimal koroner kan akımı ölçüldüğünde diyabetik kişilerde diyabetik olmayanlara göre daha az artma olmakta yani CFR azalmış olarak görülmektedir17,18. Biz de çalışmamızda öncellikle diyabetik hastalar ile kontrol hastalarını karşılaştırdık. Kontrol grubunun koroner akım rezervi(CFR) $2.41 \pm 0.40$ olarak saptanırken diyabetik hasta grubunda CFR $1.74 \pm 0.33$ idi. Her iki grup arasında CFR yönünden anlamlı farklılık saptandı. Farklılı̆̆ın oluşmasında hem bazal koroner akımların diyabetik grupta daha yüksek olması $(29,2+$ $8.87 / 24,26+3,92$, $\mathrm{p}=0.011$ ) hem de hiperemik koroner akımların daha düşük olması $(49,46+$ $13,44 / 58,39+12,43, \quad \mathrm{p}<0.0001)$ katkıda bulunmuştur. Yokoyama ve arkadaşları asemptomatik tip 2 diyabetes mellituslu hastalarda miyokard perfüzyon sintigrafisi ile miyokardiyal akım rezervi incelemesi yapmışlardır. Diyabetik grup ile kontrol grubu arasında bazal miyokard kan akımı açısından fark bulunmamış, fakat hem hiperemik miyokardiyal kan akımı hem de miyokardiyal akım rezervi diyabetik grupta kontrol grubuna göre daha düşük bulunmuştur ${ }^{19}$. Bizim çalışmamızda farklı olarak bazal miyokardial kan akımı ölçümleri de diyabetik hastalarda daha yüksek saptanmıștır. $\mathrm{Bu}$ farklılığın oluşmasında diyabetik hastalardaki ciddi epikardial koroner darlık oranının daha fazla olmasından kaynaklanabileceğini düşündük. Ayrıca daha önce yapılan bir çalışmada olduğu gibi20, çalışmamızda diyabetik hastalarda diyabetin süresi CFR azalan değerleri arasında negatif korelasyon saptanmış $(\mathrm{r}=-0.368, \mathrm{p}<$ 0.0001 ) ve insülin almakta olan diyabetik hastaların HBA1C değerleri daha yüksek, CFR değerlerinin daha düşük olduğu görülmüştür.

Hiperglisemi endotel bağımlı vazodilatasyonu bozmaktadır. Hipergliseminin düzeltilmesi mikrovasküler yataktaki arteriyollerin endotel bağımlı vazodilatasyonunun düzeltilmesine katkıda bulunarak CFR'yi yükseltmektedir. Çalışmamızda diyabetik hastalarda koroner akım rezervi (CFR) ile HbA1C arasinda ters yönde olacak şekilde $(r=-0.336, p=0.003)$ anlamlı korelasyon saptandı. Diyabetik kardiyomiyopati genellikle kendini başlangıçta diyastolik fonksiyon bozukluğu ile belli etmektedir. Doppler ekokardiyografi ile saptanan diyastolik fonksiyon bozukluğu diyabetin erken döneminde gözlenen bir özelliktir ${ }^{21}$. Çalışmamızda kontrol grup ile tüm diyabetik grubun sol ventrikül diyastolik fonksiyon parametreleri karşılaştırıldığında, diyabetik grupta diyastolik parametrelerin bozulmuş olduğu ve relaksasyon bozukluğu gösterdiği saptanmıştır. E/A oranı kontrol grubunda $1.09 \pm 0.29$, diyabetik grupta $0.81 \pm$ $0.18(\mathrm{p}<0.000)$ olarak saptanmıștır.

Koroner akım rezervi endotel fonksiyon 
bozukluğunu göstermekle beraber koroner arter darlıklarından da etkilenir. Koroner arter darlığı \% 85'in üzerine çıkmadıkça bazal akım hızı değişmemektedir. Hiperemik faz ise koroner arterde \%50 darlıktan sonra bozulmaya başlamaktadır ${ }^{22}$. Çalışmamızda diyabetik hastalarda koroner arterlerinde en az \%50 darlık olan hastaları göstermek için CFR cut-off değer hesaplanmıştır. 83 diyabetik hastadan koroner anjiyografi yapılan 79 tanesinin koroner anjiyografi sonuçları darlık düzeylerine göre sınıflandırılmıştır. Darlık saptanmayan hastalar (grup 0), \%50'ye kadar olan darlıklar (grup 1), solana koroner dişı koroner arterlerde\%50-70 arasındaki darlıklar (grup 2) ve sol ana koroner arterde $>\% 50$ ile diğer koroner arterlerde > \%70 darlık olanlar (grup 3) diye 4 grup altında incelenmiştir. Koroner anjiyografi yapılan diyabetik hastalarda ROC analizi ile hesaplanan CFR değerinin 1.65 olması \%80 sensitivite, \%81 spesifite ile herhangi bir koroner arterde \% 50 ve üzeri darlık varlığını öngörmektedir. Eğri altında kalan alan : 0,888 ( 0,811-0,965; p< $0,0001)$ saptanmıștır. Caiati ve arkadaşlarının çalışmasında, LAD'de \%70'in üzerinde darlık olanlarda TTE ile ölçülen CFR <2 olduğunda $\% 86$ duyarlılık, \%90 özgüllük ile KAH saptanmıştır ${ }^{28}$. $\mathrm{Bu}$ çalışmada sadece LAD darlıkları hesaplamaya katılmışken bizim çalışmamızda LAD dışı darlıklar da hesaplamaya dahil edilmiştir. $\mathrm{Bu}$ da çalışmamızda sensitive ve spesifitenin biraz daha düşük olmasını açıklamaktadır. Çalışmamızda aynı zamanda CFR değerleri ile koroner arter hastalığ ciddiyeti arasında anlaml korelasyon saptanmıştır. ( $\mathrm{r}=-0.653$, $\mathrm{p}<0.0001)$. Koroner arter hastalığl ciddiyeti arttıkça CFR değerlerinin korele olarak düştüğü görülmektedir. Nakanishi H. ve arkadaşlarının yaptığı çalışmada koroner BT anjiyografide $\% 70$ ve üzeri darlık saptanan hastalarda konvansiyonel koroner anjiyografi öncesi ekokardiyografik CFR ölçümü yapmışlardır.
Belirledikleri cut-off CFR değerleri (LAD için 2,Cx ve RCA için 2.1) ile kombine ettiklerinde $\% 94$ spesifite ile koroner arterlerde \%70 ve üzeri darlık varlığını saptamışlardır ${ }^{23}$. Hastalarda CFR ile koroner BT anjiyografi kombine edildiğinde duyarlılık ve özgüllügün arttığl görülmektedir. Ancak kontrast kullanım gerekliliği, radyasyon maruziyeti ve artan maliyet düşünüldügünde, tarama testi olarak kullanılması mantıklı görülmemektedir. Çalışmamızda cut-off olarak belirlenen CFR değeri sensitivite ve spesifitesi göz önünde bulundurulduğunda tarama yöntemi olarak kullanılabileceği kanısını oluşturmaktadır. Efor testinin duyarlılık ve özgüllügünü araștıran çalışmalar koroner arter hastalığı ciddiyetinden bağımsızdır. Buna karşın çalışmamızda belirlenen cut-off değer daha önemli bir bulgu olarak doğrudan ciddi koroner arter hastalığının göstergesidir.

Koroner anjiyografi yaplan 79 diyabetik hastanın 68 tanesine medikal takip kararı verilirken;5 hastaya stent implantasyonu, 6 kişiye de CABG operasyonu yapılmıştır. ROC analizi ile koroner arter darlığı göstergesi olarak belirlenen CFR:1.65 değerine göre hastalar sınıflandırıldığında, PCI veya CABG uygulanan hastaların \%81,8 inde $(n=9)$ CFR < 1.65 saptanırken,\%18,2'sinde ise CFR >1.65 saptandı. Medikal olarak takip edilen hastaların \%29,4'ünde ( $n=20)$ CFR <1.65 saptanmıştır. PCI veya CABG uygulanan hastalarda CFR değerinin < 1.65 olması lehine anlamlı farklılık saptand $(\mathrm{p}=0.001)$. Uygulanan tedavi şekline göre CFR ile tedavi şekli arasında medikalden CABG'ye doğru anlamlı derecede korelasyon tespit edildi $(\mathrm{r}=-422, \mathrm{p}<0.0001)$. CABG uygulanan hastaların PCI uygulanan hastalara göre daha komplike ve daha çok koroner darlığa sahip oldukları düşünüldüğünde bu bulgular bize CFR değerinin revaskülarize edilmesi gereken lezyon kompleksliği açısından da bilgi verdiğini göstermektedir. 


\section{SONUÇ}

Diabetik hastalarda, kılavuzların önerdiği klasik risk skorlamalarının yanında efor testinin yapılamadığı hastalarda veya düşük duyarlılık ve özgüllük sahip olması nedeniyle alternatif yöntemler düşünüldügünde basit, ucuz ve hastaya zarar vermeyen non-invaziv bir yöntem olan CFR ölçümünün göz önüne alınması, hem koroner arter hastalığının tespitinde hem de prognozun öngörülmesine katkıda bulunacaktır. İlerleyen dönemlerde bualandadahaçoksayıdahastaileyapılacakyeniç alışmalarileCFR'ınasemptomatikdiyabetiklerde taramayöntemiolarak kullanılabileceğini düşünmekteyiz.

Etik Kurul Kararı: Çalışma için İstanbul Tıp Fakültesi 24.09.2013 tarihli 1333 sayı ile etik kurulundan onay alınd.

Çıkar Çatışması Beyanı: Yazarlar çıkar çatışması olmadığını bildirmişlerdir.

Finansal Destek: Bu çalışma herhangi bir fon tarafından desteklenmemiştir.

Declaration of Conflicting Interests: The authors declare that they have no conflict of interest.

Financial Disclosure: No financial support was received.

\section{KAYNAKLAR}

1. Dülek, H. , Vural, Z. T. , Gönenç, İ. Kardiyovasküler Hastalıklara Etki Eden Faktörlerin Değerlendirilmesi ve Kardiyovasküler Risk Skorlamalarının Karşılaştırılması. Dicle Tıp Dergisi 2019; 46: 449-59.

2. Abacı A. Kardiyovasküler risk faktörlerinin ülkemizdeki durumu, Türk Kardiyol Dern Arş - Arch Turk Soc Cardiol. 2011; 39 Suppl4: 1-5.

3. Arnett DK, Blumenthal RS, Albert MA, et al. 2019 ACC/AHA guideline on the primary prevention of cardiovascular disease: a report of the American College of Cardiology/American Heart Association Task Force on Clinical Practice Guidelines. Circulation. 2019; 140: e596-e646.
4. Schmidt AM. Diabetes Mellitus and Cardiovascular Disease. Arterioscler Thromb Vasc Biol. 2019; 39: 558-68.

5. United Kingdom Prospective Diabetes Study (UKPDS). 13: relative efficacy of randomly allocated diet, sulphonylurea, insulin, or metformin in patients with newly diagnosed non-insulin dependent diabetes followed for three years. Br. Med. J. 1995; 310: 83-8.

6. Caballero, A.E. Endothelial dysfunction in obesity and insulin resistance: a road to diabetes and heart disease. Obes. Res. 2003; 11: 1278-89.

7. López-Jiménez F, Cortés-Bergoderi M. Update: systemic diseases and the cardiovascular system (i): obesity and the heart. Rev Esp Cardiol. 2011; 64: 140-9.

8. Knapp M, Tu X, Wu R. Vascular endothelial dysfunction, a major mediator in diabetic cardiomyopathy. Acta Pharmacol Sin. 2019; 40: 1-8. doi: 10.1038/s41401-018-0042-6.

9. Selthofer-Relatic K, Mihalj M, Kibel A, et al. Coronary Microcirculatory Dysfunction in Human Cardiomyopathies: A Pathologic and Pathophysiologic Review. Cardiol Rev. 2017; 25: 165-78.

10. Sicari R, Cortigiani L. The clinical use of stress echocardiography in ischemic heart disease. Cardiovasc Ultrasound. 2017; 15: 7. doi: 10.1186/s12947-017-0099-2.

11. Barthelemy O, Le Feuvre C, Timsit J. Silent myocardial ischemia screening in patients with diabetes mellitus.Arq Bras Endocrinol Metabol. 2007; 51: 285-93.

12. Alley H, Owens CD, Gasper WJ, et al. Ultrasound assessment of endothelial-dependent flowmediated vasodilation of the brachial artery in clinical research. J Vis Exp. 2014; 92: e52070.

13. Ramezankhani A, Azizi F, Hadaegh F, Momenan AA. Diabetes and number of years of life lost with and without cardiovascular disease: a multi-state homogeneous semi-Markov model. Acta Diabetol. 2018; 55: 253-62.

14. Bravo PE, Psaty BM, Di Carli MF, Branch KR. Identification of coronary heart disease in 
asymptomatic individuals with diabetes mellitus: to screen or not to screen. Colomb Med (Cali). 2015; 46: 41-6.

15. Vigili de Kreutzenberg S, Solini A, Vitolo E, et al. Silent coronary heart disease in patients with type 2 diabetes: application of a screening approach in a follow-up study. J Diabetes Complications. 2017; 31: 952-7.

16. Veillet-Chowdhury M, Blankstein R. Is there a role for screening asymptomatic patients with diabetes? Expert Rev Cardiovasc Ther. 2015; 13: 589-91.

17. Dankowski R, Wierzchowiecki M, Naskret D, et al. Association between retinopathy, microalbuminuria and coronary perfusion in young patients with type 1 diabetes mellitus. Kardiol Pol. 2008; 66: 262-8.

18. Glatz JFC, Dyck JRB, Des Rosiers C. Cardiac adaptations to obesity, diabetes and insulin resistance. Biochim Biophys Acta Mol Basis Dis. 2018; 1864: 1905-7.

19. Yokoyama I. et al. Reduced myocardial flow reserve in non-insulin dependent diabetes mellitus. J Am Coll Cardiol. 1997; 30: 1472-7.
20. Pitkanen O.P.,et al. Coronary flow reserve is reduced in young men with IDDM.

Diabetes.1998; 47: 248-54.

21. Holovko T, Shevchenko N, Bogmat L, et al. Adaptive capabilities of the cardiovascular system in adolescents with non-inflammatory myocardial pathology, taking into account morphofunctional indicators of the heart. Georgian Med News. 2019; 296: 42-8.

22. Hage FG, AlJaroudi WA. Review of cardiovascular imaging in The Journal of Nuclear Cardiology in 2014: Part 2 of 2: Myocardial perfusion imaging. J Nucl Cardiol. 2015; 22: 714-9.

23. Nakanishi H., Hirata K. et al. Incremental value of coronary flow velocity reserve, measured by transthoracic echocardiography, compared with computed tomography angiography alone, for detecting flow-limiting coronary stenoses. Journal of the American Society of Echocardiography. 2014; 27: 1230-7. 